\title{
Anti-thrombotic Activity of KBT-3022 in Experimental Models of Thrombosis
}

\author{
Koichi Yokota ${ }^{1}$, Akira Yamashita ${ }^{1}$ and Minoru $\mathrm{Oda}^{2}$ \\ ${ }^{3}$ New Drug Research Laboratories, Kanebo, Ltd., 5-90, Tomobuchi-cho 1-chome, Mivakojima-ku, Osaka 534, Japan \\ ${ }^{2}$ Research Laboratories, Torii Pharmaceutical Co., Ltd., 2-1, Ohnodai I-chome, Midori-ku, Chiba 267, Japan
}

Received July 1, 1994 Accepted March 25, 1995

\begin{abstract}
In this study, we investigated the effects of KBT-3022 (ethyl 2-[4,5-bis(4-methoxyphenyl)thiazol-2-yl]pyrrol-1-ylacetate), a potent and long-lasting anti-platelet agent, in several experimental thrombosis models and compared them with those of other anti-platelet drugs. Oral administration of KBT3022 prevented arachidonic acid-induced death due to pulmonary embolism in mice and rabbits with respective $\mathrm{ED}_{50}$ values of 0.29 and $0.12 \mathrm{mg} / \mathrm{kg}$. The protective effect of acetylsalicylic acid (ASA) against mortality was weaker than that of KBT-3022, and ticlopidine hydrochloride (TP) showed no such effect in these models. In a guinea pig arterio-venous shunt model, the inhibition by KBT-3022 of thrombus formation on a silk thread inserted into the shunt was dose-dependent and 300 and 30 times more potent than the inhibition obtained with ASA and indomethacin, respectively. In a model of aortic thrombosis induced by perivascular application of $20 \%$ silver nitrate solution, KBT-3022 $(1 \mathrm{mg} / \mathrm{kg}, \mathrm{p} . \mathrm{o}$. $)$ inhibited thrombus formation significantly, ASA (100 mg/kg, p.o.) tended to inhibit it, and TP had no effect. However, in a stasisinduced venous thrombosis model in guinea pigs, TP inhibited thrombus formation significantly, but KBT3022 and ASA were ineffective. These results suggest that KBT-3022 may be a useful drug for the treatment and/or prophylaxis of thrombus formation in shunts and aortic thrombosis.
\end{abstract}

Keywords: Anti-platelet agent, KBT-3022, Acetylsalicylic acid, Ticlopidine, Thrombosis model

Platelets are well known to play an important role in thrombus formation, and agents that suppress platelet activation inhibit thrombosis in animal models and clinical situations (1). A new compound synthesized by Kanebo (2), KBT-3022 (ethyl 2-[4,5-bis(4-methoxyphenyl)thiazol2-yl]pyrrol-1-ylacetate, Fig. 1), inhibits platelet aggregation induced by arachidonic acid (AA) and collagen, and serotonin release from platelets induced by collagen in

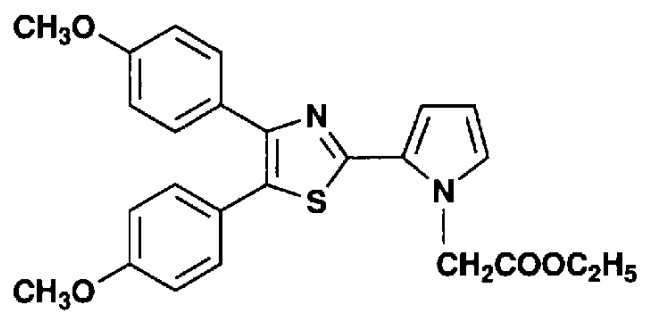

Fig. 1. Chemical structure of KBT-3022 (ethyl 2-[4,5-bis(4-methoxyphenyl)thiazol-2-yl]pyrrol-1-ylacetate). vitro (3). Oral administration of KBT-3022 inhibits AAand collagen-induced platelet aggregation and platelet retention in guinea pigs; it was approximately 100 times more potent than acetylsalicylic acid (ASA), and its effects were longer lasting $(3,4)$. These findings suggest that KBT-3022 may have anti-thrombotic activity in vivo. To clarify this, the aim of this study was to evaluate its activity in experimental thrombosis models and compare them with two anti-platelet drugs, ASA (5) and ticlopidine hydrochloride (TP) (6), which were most widely studied in clinical trials (7) and were reported to be effective in the prevention of stroke after transient ischemic attacks (8). Furthermore, in an extracorporeal shunt model, the effect of KBT-3022 was also compared with that of indomethacin, a cyclooxygenase inhibitor. Preliminary results of this work were presented at the 11th International Congress of Pharmacology, Amsterdam, The Netherlands, July 1990 (4). 


\section{MATERIALS AND METHODS}

\section{Animals}

Male mice (ddY strain, weighing 18-21 g) from Japan SLC (Hamamatsu), male guinea pigs (Hartley strain, weighing 320-460 g) from Japan SLC or Keari (Osaka) and male Japanese albino rabbits (weighing $2.3-3.4 \mathrm{~kg}$ ) from Kitayama Labes (Ina) were used. These animals were sacrificed by administration of sodium pentobarbital (Abbott Laboratories, North Chicago, IL, USA), unless indicated otherwise.

\section{Drugs and chemicals}

The KBT-3022 was synthesized in the New Drug Research Laboratories at Kanebo, TP was extracted from Panaldine ${ }^{\widehat{\mathbb{R}}}$ tablets purchased from Daiichi Pharmaceutical (Tokyo) and purified at Kanebo, and ASA was purchased from Wako Pure Chemical Industry (Osaka). Indomethacin was purchased from Sigma Chemical Co. (St. Louis, MO, USA). These compounds were dissolved or suspended in $0.5 \%$ polyoxyethylene sorbitan monooleate solution for oral administration. Control animals were given an equivalent volume of the vehicle. Heparin (sodium salt) was purchased from Shimizu Pharmaceutical Co. (Shimizu) and was dissolved in physiological saline for intravenous administration. The AA (sodium salt) was purchased from Sigma Chemical Co. All the other reagents used were of reagent grade.

\section{Effect on $A$ A-induced death in mice}

$\mathrm{AA}(100 \mathrm{mg} / \mathrm{kg})$ was injected into the tail veins of mice at a rate of $0.02 \mathrm{ml} / \mathrm{sec}$, and the mortality was observed 30 min thereafter (9). The AA was dissolved in saline and adjusted to a final concentration of $10 \mathrm{mg} / \mathrm{ml}$. Each test compound was administered orally $3 \mathrm{hr}$ before the AA challenge.

\section{Effect on AA-induced death in rabbits}

AA $(1.7 \mathrm{mg} / \mathrm{kg})$ was injected into the marginal ear vein of rabbits at a rate of $0.1 \mathrm{ml} / \mathrm{sec}$, and the mortality was observed $30 \mathrm{~min}$ thereafter (10). The AA was dissolved in saline and adjusted to a final concentration of $3.4 \mathrm{mg} / \mathrm{ml}$. A preliminary experiment showed that $1.7 \mathrm{mg} / \mathrm{kg} \mathrm{AA}$ caused death in $100 \%$ of untreated rabbits. Each test compound was administered orally $3 \mathrm{hr}$ before the AA challenge.

\section{Effect on thrombus formation in extracorporeal shunts}

Extracorporeal shunts were established in guinea pigs using the method of Umetsu and Sanai (11) with slight modifications. As the bioavailability of KBT-3022 is low for rats after oral administration (12), we used guinea pigs instead of rats to evaluate the effects of KBT-3022 and other drugs. Briefly, the animals were anesthetized with sodium pentobarbital, and the right carotid artery and left jugular vein were exposed through a transverse cervical incision. One end of a polyethylene cannula was inserted in the right carotid artery and $10 \mathrm{U} / \mathrm{ml}$ heparin $(15 \mathrm{U} / \mathrm{kg})$ was injected slowly through the cannula; the other end of the cannula, in which a silk thread was placed, was inserted in the left jugular vein, and extracorporeal blood circulation was started. After circulation for $15 \mathrm{~min}$, the middle portion of the cannula was removed, and the thread with thrombus was carefully pulled out and weighed immediately. The thrombus weight was obtained by subtracting the wet weight of the silk thread (4 $\mathrm{mg}$ ) from the weight of the thread plus thrombus. Three 15-min periods of extracorporeal flow were carried out in each guinea pig to obtain a total thrombus weight. Each test compound was administered orally $3 \mathrm{hr}$ before establishment of the first shunt.

\section{Effect on silver nitrate-induced aortic thrombus forma- tion}

Aortic thrombus formation was induced by the method of Zimmermann et al. (13) with slight modifications. In brief, rabbits were anesthetized with urethane $(1.4 \mathrm{~g} / \mathrm{kg}$, i.p.) and the right carotid artery was exposed through a transverse cervical incision. Fifty microliters of $20 \%$ silver nitrate solution was applied perivascularly to a $2-\mathrm{cm}-$ long segment of the artery. This segment was kept in a polypropylene groove for $3 \mathrm{hr}$ and then dissected and cut open longitudinally. The thrombus was removed carefully and weighed immediately. Each test compound was administered orally $2 \mathrm{hr}$ before silver nitrate application.

\section{Effect on stasis-induced venous thrombus formation}

Stasis-induced venous thrombus formation was induced by the method of Bernat et al. (14) with slight modifications. Briefly, guinea pigs were anesthetized with sodium pentobarbital ( $30 \mathrm{mg} / \mathrm{kg}$, i.p.), and a mid-line abdominal incision was made. The inferior vena cava was exposed, and all side branches of the inferior vena cava below the left renal vein were ligated. The inferior vena cava was ligated just below the left renal vein, and then the wound was closed with Michelle clips. The abdomen was reopened $2 \mathrm{hr}$ later, the inferior vena cava was clamped $2 \mathrm{~cm}$ below the ligature, and the blood in the vascular segment was drained by puncturing it with a needle. This segment was cut open longitudinally, the thrombus was removed, dried for $24 \mathrm{hr}$ in a vacuum desiccator and the dry weight was measured. Heparin was administered intravenously $10 \mathrm{~min}$ before, and the other test compounds were administered orally $3 \mathrm{hr}$ before ligation. 
Table 1. Protective effects of KBT-3022, ASA and TP on AA-induced mortality in mice

\begin{tabular}{lccccccccc}
\hline \multirow{2}{*}{ Compound } & \multicolumn{7}{c}{ Dose $(\mathrm{mg} / \mathrm{kg}, \mathrm{p} .0)}$. & & ED $_{50}$ (95\% C.L.) \\
\cline { 2 - 8 } & 0.03 & 0.1 & 0.3 & 1 & 3 & 10 & 30 & 100 & \\
\hline KBT-3022 & $5 / 5^{\mathrm{a}}$ & $5 / 5$ & $1 / 5$ & $1 / 5$ & & & & & $0.29(0.12-0.87)$ \\
ASA & & & & & & $4 / 5$ & $2 / 5$ & $0 / 5$ & $21.3(5.5-59)$ \\
TP & & & & & & & $5 / 5$ & $5 / 5$ & \\
\hline
\end{tabular}

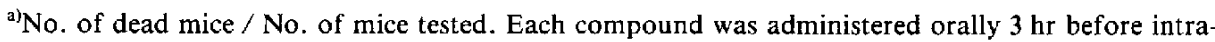
venous injection of AA $(100 \mathrm{mg} / 10 \mathrm{ml} / \mathrm{kg})$. ASA: acetylsalicylic acid, TP: ticlopidine.

\section{Statistics}

All the data are expressed as means \pm S.E.M. The statistical significance of differences between them was evaluated by one-way analysis of variance (ANOVA) followed by Dunnett's test. Differences at $P$ values of less than 0.05 were considered to be statistically significant. The $\mathrm{ED}_{50}$ values for AA-induced death in mice and rabbits were calculated by Probit analysis (15) and the upand-down method (16), respectively.

\section{RESULTS}

\section{Effect on $A A$-induced death in mice}

All the mice injected with AA $(100 \mathrm{mg} / \mathrm{kg})$ died within a few minutes. Pretreatment with KBT-3022 $(0.3$ and 1 $\mathrm{mg} / \mathrm{kg}$ ) protected them from death, and its $\mathrm{ED}_{50}$ was $0.29 \mathrm{mg} / \mathrm{kg}$ (Table 1). Under these experimental conditions, ASA was also effective; its $\mathrm{ED}_{50}$ was $21.3 \mathrm{mg} / \mathrm{kg}$. $\mathrm{TP}$, however, even at $100 \mathrm{mg} / \mathrm{kg}$, afforded no protection against mortality.

\section{Effect on AA-induced death in rabbits}

All the rabbits injected with $\mathrm{AA}(1.7 \mathrm{mg} / \mathrm{kg})$ died within a few minutes. Pretreatment with KBT-3022 protected against mortality, and its $\mathrm{ED}_{50}$ value was 0.12 $\mathrm{mg} / \mathrm{kg}(\mathrm{n}=10)$. ASA also showed a protective effect $\left(E D_{50}, 5.9 \mathrm{mg} / \mathrm{kg}, \mathrm{n}=10\right.$ ), whereas $\mathrm{TP}$, even at $320 \mathrm{mg} / \mathrm{kg}$, did not.

\section{Effect on thrombus formation in extracorporeal shunts}

Pretreatment with KBT-3022 $(0.1$ to $1 \mathrm{mg} / \mathrm{kg})$ inhibited thrombus formation in a dose-dependent manner; and at 0.3 and $1 \mathrm{mg} / \mathrm{kg}$, it significantly reduced the weight of thrombus formed by $48.8 \%$ and $51.9 \%$, respectively, compared with the control (Fig. 2). ASA of 30 and 100 $\mathrm{mg} / \mathrm{kg}$ inhibited thrombus formation significantly by $34.6 \%$ and $53.4 \%$, respectively, but TP $(300 \mathrm{mg} / \mathrm{kg})$ had no effect. Indomethacin of 3 and $10 \mathrm{mg} / \mathrm{kg}$ inhibited thrombus formation significantly by $24.6 \%$ and $45.4 \%$, respectively.

\section{Effect on silver nitrate-induced aortic thrombus forma- tion}

As shown in Fig. 3, perivascular application of $20 \%$ silver nitrate solution to the carotid artery in rabbits resulted in thrombus formation, and the mean thrombus

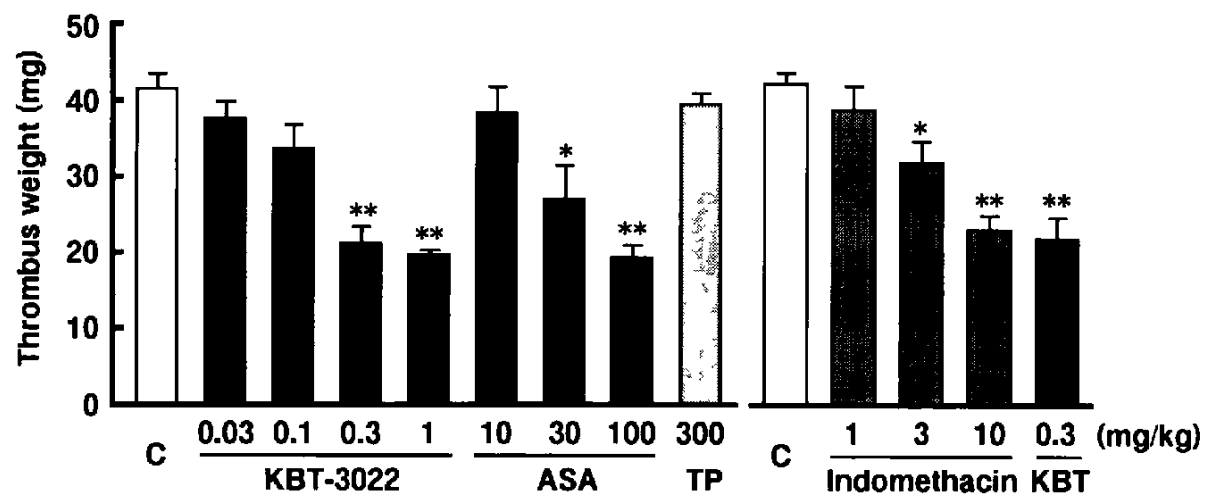

Fig. 2. Effects of KBT-3022, ASA, TP and indomethacin on thrombus formation in arterio-venous shunts in guinea pigs. Each compound was administered orally $3 \mathrm{hr}$ before the establishment of an extracorporeal circulation. Each column and vertical bar shows the mean and S.E.M., respectively, of $6-13$ animals. ${ }^{*} \mathrm{P}<0.05$, ${ }^{* *} \mathrm{P}<0.01$, significantly different from the control (Dunnett's test). KBT: KBT-3022, ASA: acetylsalicylic acid, TP: ticlopidine. 


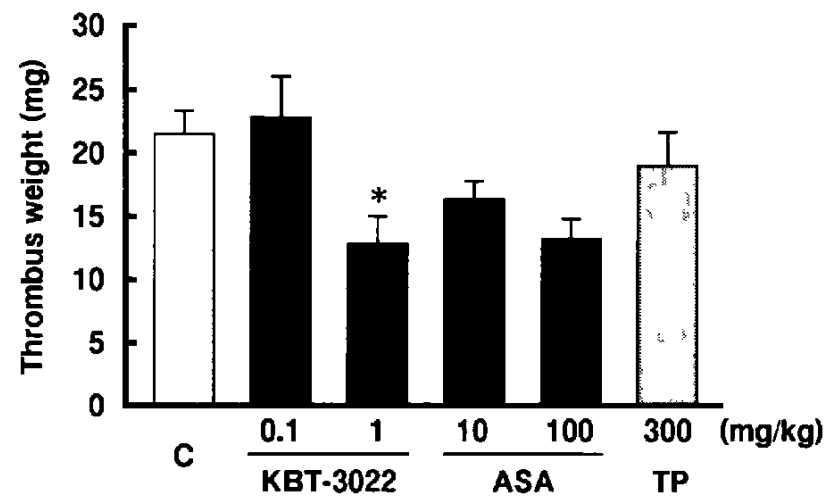

Fig. 3. Effects of KBT-3022, ASA and TP on thrombus formation induced by the application of silver nitrate solution to the common carotid artery in rabbits. Each compound was administered orally 2 hr before vascular injury induction. Each column and vertical bar shows the mean and S.E.M., respectively, of 10-12 animals. ${ }^{*} \mathbf{P}<0.05$, significantly different from the control (Dunnett's test). ASA: acetylsalicylic acid, TP: ticlopidine.

weight was $21.5 \pm 1.8 \mathrm{mg}(\mathrm{n}=12)$. Pretreatment with $\mathrm{KBT}-3022(1 \mathrm{mg} / \mathrm{kg})$ significantly reduced the weight of thrombus formed by $40 \%$, ASA $(100 \mathrm{mg} / \mathrm{kg})$ tended to reduce thrombus formation, but TP $(300 \mathrm{mg} / \mathrm{kg})$ had no effect.

\section{Effect on stasis-induced venous thrombosis}

The weight of the thrombus formed as a result of ligating the inferior vena cava in guinea pigs increased in a time-dependent manner from 1 to $3 \mathrm{hr}$ after ligation. As the thrombus weight was submaximal at $2 \mathrm{hr}$ (data not shown), we measured it $2 \mathrm{hr}$ after ligation. Thrombus formation in the vein was not affected by pretreatment with KBT-3022 or ASA (both at $300 \mathrm{mg} / \mathrm{kg}$ ), respectively

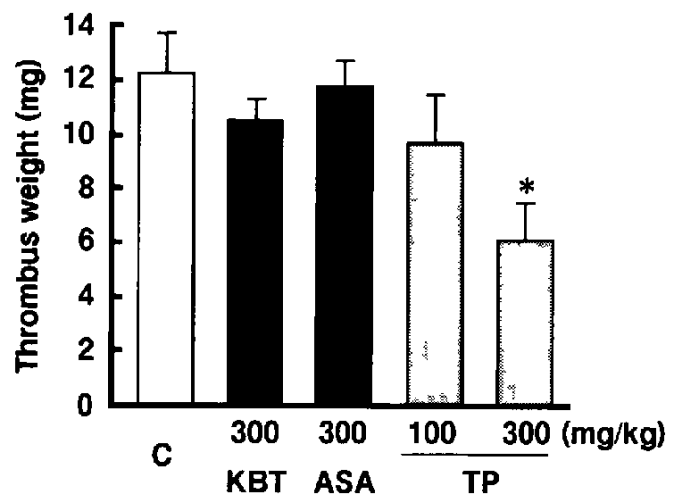

Fig. 4. Effects of KBT-3022, ASA and TP on thrombus formation induced by ligation of the inferior vena cava in guinea pigs. Each column and vertical bar shows the mean and S.E.M., respectively, of 5 animals. ${ }^{*} \mathrm{P}<0.05$, significantly different from the control (Dunnett's test). KBT: KBT-3022, ASA: acetylsalicylic acid, TP: ticlopidine.
(Fig. 4), whereas TP $(300 \mathrm{mg} / \mathrm{kg})$ inhibited it significantly. Heparin $(30 \mathrm{U} / \mathrm{kg}$, i.v. $)$ significantly inhibited the thrombus formation (data not shown).

\section{DISCUSSION}

Oral administration of KBT-3022 prevented the mortality of mice and rabbits caused by an intravenous injection of $\mathrm{AA}$, and it was approximately 20-100 times more potent than ASA. AA-induced death in these animals is believed to be attributable to platelet aggregation and constriction of blood vessels and/or bronchi caused by thromboxane (TX) $\mathrm{A}_{2}$ (17). Cyclooxygenase inhibitors (18-21), TXA 2 synthetase inhibitors (22-24) and TXA /prostaglandin $(\mathrm{PG})$ endoperoxide receptor antagonists $(25,26)$ have been reported to prevent AA-induced mortality in mice and rabbits. In a previous study, we showed that KBT-3022 and its metabolite, desethyl KBT-3022, inhibited the activity of ovine seminal gland cyclooxygenase (respective $\mathrm{IC}_{50}: 0.69$ and $0.43 \mu \mathrm{M}$ ) and leukocyte 5-lipoxygenase (respective $\mathrm{IC}_{50}: 1.6$ and $5.2 \mu \mathrm{M}$ ); that desethyl KBT-3022 inhibited the specific binding of $\left[{ }^{3} \mathrm{H}\right] \mathrm{U} 46619$ to guinea pig platelets with an $\mathrm{IC}_{50}$ value of $19 \mu \mathrm{M}$; and that after oral administration of KBT-3022 to guinea pigs, production of both $\mathrm{TXB}_{2}$ in serum and 6-keto-PGF ${ }_{1 \alpha}$ from the aorta was inhibited ex vivo (27). Therefore, prevention of AA-induced mortality by KBT-3022 may result from inhibition of the generation and actions of $\mathrm{TXA}_{2}$ in vivo. TP did not prevent AA-induced mortality. It has been reported not to inhibit AA metabolism ex vivo despite inhibiting AA release from phospholipids in platelets (28).

In rats, Umetsu and Sanai (11) observed that the thrombus that developed in an arterio-venous shunt was comprised primarily of platelets, and its formation was inhibited by pretreatment with ASA. In the guinea pig shunt model, the thrombus consisted mainly of platelets and fibrin, and ASA reduced its formation to half. In this model, KBT-3022 was approximately 300 times more potent an inhibitor than ASA. As KBT-3022 inhibited AAand collagen-induced aggregation and platelet retention on a column of glass beads in guinea pigs at the same dose as that inhibiting thrombus formation (3), KBT-3022 appeared, in common with ASA, to inhibit platelet activation and deposition in thrombi in this model.

Indomethacin also inhibited thrombus formation, but its potency was approximately 30 times weaker than that of KBT-3022. We observed that the inhibitory effects of KBT-3022 and desethyl KBT-3022 on collagen-induced guinea pig platelet aggregation were approximately 100 times more potent than that of indomethacin in vitro (unpublished data). Moreover, we have described previously that the inhibition of ovine seminal gland cyclooxygenase 
activity by indomethacin was approximately 3 and 4 times weaker than that by KBT-3022 and its metabolite desethyl KBT-3022, respectively (27). On the other hand, Nakada et al. (29) reported that radioactivity in platelets and the aorta was 2.4-15.7 times higher and approximately 0.5 times lower than that in plasma, respectively, after oral administration of $\left[{ }^{14} \mathrm{C}\right] \mathrm{KBT}-3022$ to mice. Thus, these results suggest that the potent anti-platelet aggregating effect of KBT-3022 may result from not only its potency to inhibit cyclooxygenase but also its ability for easy distribution into platelets, and its potent anti-platelet effects may reflect the anti-thrombotic effects.

TP failed to inhibit thrombus formation in the guinea pig shunt model, although it has been demonstrated to have a superior inhibitory effect to ASA in the rat shunt model $(30,31)$. This discrepancy may be attributable to their less potent anti-aggregatory effects in guinea pigs than rats (32).

Perivascular application of silver nitrate solution to the carotid artery of rabbits appeared to produce vessel wall necrosis and consequent activation of the platelet and coagulation systems (33). ASA had a tendency to inhibit thrombus formation in this model, as described previously (25), and KBT-3022 was approximately 100 times more potent than ASA in this respect. Both $\mathrm{TXA}_{2}$ synthetase inhibitors and $\mathrm{TXA}_{2} / \mathrm{PG}$ endoperoxide receptor antagonists also have been reported to inhibit thrombus formation in this model $(22,25)$, but TP showed no such inhibitory effects. We observed that oral administration of TP to rabbits partially inhibited platelet aggregation induced by ADP, but not that induced by AA, collagen or PAF (unpublished data). Therefore, in rabbits, $\mathrm{TXA}_{2}$ may play a more important role in thrombus formation caused by vessel wall lesion than ADP.

Thrombin generation, which induces fibrin clot formation and activates platelets, is regarded as a major mechanism of human venous thrombus formation (34). In the guinea pig stasis-induced venous thrombosis model we used, pretreatment with ASA did not prevent thrombus formation; heparin suppressed it (data not shown), as described previously $(14,35)$; and KBT-3022 had no effect. These findings indicate that activation of platelets may play a minimal, if any, role in stasis-induced venous thrombus formation in guinea pigs. TP, however, did inhibit venous thrombus formation in this model, as described by Bernat et al. (14) and Kumada et al. (36), although its mode of action has yet to be elucidated.

These results suggest that KBT-3022 may be a candidate for the treatment and/or prophylaxis of thrombus formation in shunts and aortic thrombosis.

\section{Acknowledgment}

We wish to thank Dr. Takayuki Sukamoto (New Drug Research Laboratories, Kanebo, Ltd.) for reading and commenting on the manuscript.

\section{REFERENCES}

1 Mustard JF and Packham MA: Factors influencing platelet function: adhesion, release, and aggregation. Pharmacol Rev 22, 97-187 (1970)

2 Seko N, Yoshino K, Yokota K, Yamashita A, Ito K and Tsukamoto G: Synthesis and structure-activity relationship of new diphenylazole derivatives as potent platelet aggregation inhibitor. J Pharmacobiodyn 12, s-141 (1989)

3 Yokota K, Yamamoto N, Morimoto Y, Yamashita A and Ito K: Anti-platelet activity of KB-3022. Jpn J Pharmacol 46, Supp 190P (1988)

4 Yokota K, Yamamoto N, Yamashita A, Ito K and Nurimoto N: Anti-thrombotic effect of KBT-3022 on experimental thrombosis models. Eur J Pharmacol 183, 1841 (1990) (Abstract)

5 Vane J: Towards a better aspirin. Nature 364, 215-216 (1994)

6 Ashida $S$ and Abiko Y: Inhibition of platelet aggregation by a new agent, ticlopidine. Thromb Haemost 41, 542-550 (1978)

7 ATC (Antiplatelet Trialists' Collaboration): Collaborative overview of randomized trials of antiplatelet therapy-I: Prevention of death, myocardial infarction, and stroke by prolonged antiplatelet therapy in various categories of patients. Br Med J 308, $81-106$ (1994)

8 American Heart Association Committee: Guidelines for the management of transient ischemic attacks. Stroke 25, $1320-1335$ (1994)

9 Kohler C, Wooding $W$ and Ellenbogen L: Intravenous arachidonate in the mouse: a model for the evaluation of antithrombotic drugs. Thromb Res 9, 67-80 (1976)

10 Silver MJ, Hoch W, Kocsis JJ, Ingerman CM and Smith JB: Arachidonic acid causes sudden death in rabbits. Science 183, 1085 - 1087 (1974)

11 Umetsu $\mathrm{T}$ and Sanai K: Effect of 1-methyl-2-mercapto-5-(3pyridyl)-imidazole (KC-6141), an anti-aggregating compound, on experimental thrombosis in rats. Thromb Haemost 39, $74-83$ (1978)

12 Nakada $\mathrm{Y}$, Miyake M, Fujikawa $\mathrm{M}$, Tanizawa $\mathrm{R}$, Awata $\mathrm{N}$ and Kurotori M: Species and sex differences on the pharmacokinetics of a new anti-platelet drug, ethyl 2-[4,5-bis(4-methoxyphenyl)thiazol-2-yl]pyrrol-1-ylacetate among mice, rats and dogs. Yakuzaigaku 53, 210-220 (1993) (Abstr in English)

13 Zimmermann $R$, Zeltsch $C$ and Lange D: Estimation of thrombus formation by labeling of platelets, red cells and fibrinogen in experimental thrombosis. Thromb Res 16, 147-158 (1979)

14 Bernat A, Vallée E, Maffrand JP and Roncucci R: Antithrombotic effect of ticlopidine in a platelet-independent model of venous thrombosis. Thromb Res 37, 279-285 (1985)

15 Finney DJ: Probit Analysis, third ed. Cambridge University Press, Cambridge (1971)

16 Brownlee KA, Hodges JL Jr and Rosenblatt M: The up-anddown method with small samples. J Am Statist Assoc 48, 262-277 (1953)

17 Moncada S and Vane JR: Pharmacology and endogenous roles of prostaglandin endoperoxide, thromboxane $A_{2}$, and prostacyclin. Pharmacol Rev 30, 293-331 (1978) 
18 Rüegg M: Antithrombotic effects of sulfinpyrazone in animals: influence on fibrinolysis and sodium arachidonate-induced pulmonary embolism. Pharmacology 14, 522-536 (1976)

19 DiPasquale $G$ and Mellace D: Inhibition of arachidonic acid induced mortality in rabbits with several non-steroidal antiinflammatory agents. Agents Actions 7, 481-485 (1977)

20 Smith JB, Araki $\mathrm{H}$ and Lefer AM: Thromboxane $\mathrm{A}_{2}$, prostacyclin and aspirin: effects on vascular tone and platelet aggregation. Circulation 62, Supp V, 19-25 (1980)

21 Vigdahl RL, Ferber RH and Parrish SL: Evaluation of antiinflammatory and antithrombotic drugs in pulmonary and arterial thrombosis. Thromb Res 16, 117-127 (1979)

22 Naito J, Hiraku S and Kuga T: Thromboxane $A_{2}\left(T_{X A}\right)$ synthetase inhibition by $(E)$-3-[4-(1-imidazolylmethyl)phenyl]-2propenoic acid hydrochloride monohydrate (OKY-046) and sodium ( $E$ )-3-[4-(3-pyridylmethyl)phenyl]-2-methyl-propenoate (OKY-1581), and their medical usefulness, Pharmacometrics 27, 267-287 (1984) (Abstr in English)

23 Ushiyama S, Ito T, Asai F, Oshima T, Terada A, Matsuda $\mathrm{K}$ and Yamazaki M: RS-5186, a novel thromboxane synthetase inhibitor with a potent and extended duration of action. Thromb Res 51, 507-520 (1988)

24 Lefer AM, Okamatsu S, Smith EF III and Smith JB: Beneficial effects of a new thromboxane synthetase inhibitor in arachidonate-induced sudden death. Thromb Res 23, 265-273 (1981)

25 Stegmeier K, Pill J, Müller-Beckmann B, Schmidt FH, Witte EC, Wolff $\mathrm{H}-\mathrm{P}$ and Patscheke $\mathrm{H}$ : The pharmacological profile of the thromboxane $A_{2}$ antagonist BM 13.177. A new anti-platelet and anti-thrombotic drug. Thromb Res 35, 379-395 (1984)

26 Darius H, Smith JB and Lefer AM: Beneficial effects of a new potent and specific thromboxane receptor antagonist (SQ$29,548)$ in vitro and in vivo. J Pharmacol Exp Ther 235, $274-281$ (1985)
27 Yamashita A, Matsuo K, Yokota K, Ito K and Nurimoto S: Anti-platelet effect and mode of action of a new anti-platelet agent KBT-3022. Eur J Pharmacol 183, 340 (1990) (Abstract)

28 Ashida S and Abiko Y: Mode of action of ticlopidine in inhibition of platelet aggregation in the rat. Thromb Haemost $\mathbf{4 1}$, 436-449 (1979)

29 Nakada $Y$, Miyake M, Shimada $H$, Fujikawa M, Awata N, Kurotori $\mathrm{M}$, Arakawa $\mathrm{K}$, Ichige $\mathrm{K}$ and Hori $\mathrm{K}$ : Absorption, distribution and excretion of a new antiplatelet drug, ethyl 2[4,5-bis(4-methoxyphenyl)thiazol-2-yl]pyrrol-1-ylacetate, (KBT3022), after single oral administration in mice. Yakubutsu Dotai 9, 265-277 (1994) (Abstr in English)

30 Ashida S, Sakuma K and Abiko Y: Antithrombotic effects of ticlopidine, acetylsalicylic acid and dipyridamole in vascular shunt model in rats. Thromb Res 17, 663-671 (1980)

31 Smith JR and White AM: Fibrin, red cell and platelet interactions in an experimental model of thrombosis. $\mathrm{Br} \mathrm{J}$ Pharmacol 77, 29-38 (1982)

32 Defreyn G, Bernat A, Delebassee D and Maffrand J-P: Pharmacology of ticlopidine: a review. Semin Thromb Hemost 15, 159- 166 (1989)

33 Jansen KF and Tage-Hansen E: Dicoumarol in experimental thrombosis. Acta Chir Scand 98, $152-156$ (1949)

34 Baumgartner HR: The role of blood flow in platelet adhesion, fibrin deposition and formation of mural thrombi. Microvasc Res 5, 167-179 (1973)

35 Reyers I, Mussoni L, Donati MB and Gaetano G: Failure of aspirin at different doses to modify experimental thrombosis in rats. Thromb Res 18, 669-674 (1980)

36 Kumada $\mathrm{T}$, Ishihara $\mathrm{M}$, Ogawa $\mathrm{H}$ and Abiko $\mathrm{Y}$ : Experimental model of venous thrombosis in rats and effect of some agents. Thromb Res 18, 189-203 (1980) 